\title{
SISTEMAS AGROALIMENTARES LOCAIS E A VISÃO BASEADA EM RECURSOS: CONSTRUINDO VANTAGENS COMPETITIVAS PARA A CARNE BOVINA GAÚCHA $^{1}$
}

\author{
Guilherme Cunha Malafaia ${ }^{2}$ \\ Julio Otavio Jardim Barcellos ${ }^{3}$
}

\begin{abstract}
Resumo - Este estudo teve por objetivo discutir a viabilidade de inserção da pecuária gaúcha no ambiente competitivo do agronegócio, por meio dos Sistemas Agroalimentares Locais (SIAL). As transformações incorridas no agronegócio, decorrentes da globalização, dificultaram a competitividade de muitas empresas pecuárias gaúchas devido às suas incapacidades de atenderem aos novos padrões exigidos. Entretanto, percebe-se uma grande oportunidade para essa atividade através da penetração em nichos de mercados específicos. Nesse sentido, o conceito de SIAL ganha importância, haja vista associar estreitamente os recursos estratégicos (produtos típicos e artesanais; técnicas diferenciadas; estilos alimentares; território; recursos naturais; ações coletivas; e organização das atividades de produção). Os resultados mostraram que os SIAL podem ser alternativas viáveis de inserção para a pecuária gaúcha no ambiente competitivo, porém problemas de coordenação necessitam ser equacionados.
\end{abstract}

Palavras-chave: Sistemas Agroalimentares Locais, visão baseada em recursos, pecuária de corte.

${ }^{1}$ Recebido em 04/12/2006. Aceito em 26/02/2007.

${ }^{2}$ Professor Adjunto da Universidade de Caxias do Sul - UCS. E-mail: gcmalafa@ucs.br.

${ }^{3}$ Professor Adjunto da Universidade Federal do Rio Grande do Sul - UFRGS. E-mail: julio.barcellos@ @frgs.br 


\section{Introdução}

A crescente fragilização das empresas em face do processo de globalização, bem como as rápidas mudanças tecnológicas, faz com que novas formas de gestão se incorporem ao mundo dos negócios. O estabelecimento de relações interorganizacionais - em que empresas buscam concentrar-se em suas competências centrais, transferindo a terceiros as demais atividades não- centrais - vem cada vez mais ganhando importância no cenário dos negócios (Sterns e Peterson, 2001).

Nesse sentido, determinadas configurações socioprodutivas podem representar melhores possibilidades de enfrentamento de desafios, proporcionando vantagens competitivas para as empresas. A abordagem de aglomerados geográficos de empresas, vinculados a uma mesma cadeia produtiva, visando uma eficiência coletiva, e sustentada por aspectos institucionais, apresentaria condições para isso (Schimtz e Nadvi, 1999).

A cooperação entre empresas de um determinado grupo, localizadas geograficamente próximas, aliada aos recursos estratégicos presentes no território, são elementos importantes para criar oportunidades e novos espaços para a atuação das organizações diante do ambiente competitivo e globalizado. A concentração geográfica é um facilitador para novas conquistas, porém é necessária uma coordenação eficiente para o desenvolvimento de vantagens competitivas sustentáveis (Schimitz e Nadvi, 1999).

É nessa lógica que se buscou desenvolver este estudo, ou seja, discutir a viabilidade de construção de vantagens competitivas para a pecuária de corte gaúcha no ambiente competitivo do agronegócio por meio dos Sistemas Agroalimentares Locais. Em outras palavras, pretendeu-se buscar entender como se dá o processo de uma provável construção de vantagens competitivas, mediante o uso eficiente dos ativos estratégicos na região da Campanha Gaúcha. 


\subsection{Problema de pesquisa}

As mudanças no cenário competitivo mundial dificultam as condições de sobrevivência das empresas (Forsman e Paanamem, 2002), obrigandoas a estabelecerem relações cooperativas com vistas a obter os fatores de produção necessários à sua manutenção e sobrevivência nos mercados. Essas empresas, de modo geral, buscam estabelecer interrelações nas mais diversas formas, podendo ser estas formais ou informais, buscando enfrentar problemas comuns e/ou explorar conjuntamente as possibilidades que se oferecem, gerando com isso uma eficiência coletiva.

No que se refere ao setor agroalimentar, Cozzarin e Barry (1998) enfatizam que os desafios encontrados na competição global de alimentos têm sido bem resolvidos pelas grandes organizações. É sabido que as grandes empresas do agronegócio impuseram um modelo de internacionalização da agricultura baseado em novos padrões de dependência, o que originou a exclusão de muitos produtores do processo produtivo, em face de sua incapacidade de atenderem às exigências de grandes escalas e da padronização de produtos e processos (RequierDesjardins, 2002).

Entretanto, Forsman e Paananem (2002) afirmam que cada vez mais aumenta o interesse dos consumidores pela qualidade e segurança dos alimentos. Atributos como denominação de origem, rastreabilidade e transparência nos processos produtivos vêm ganhando espaço cada vez maior nos últimos anos. Esse interesse cria uma boa oportunidade para as empresas inserirem-se no ambiente competitivo. A diferenciação dos produtos, fruto de ações coletivas locais, por meio da criação de marcas geográficas, como forma de valorizar os usos e costumes locais, pode proporcionar um diferencial competitivo para as empresas agroalimentares.

No que se refere à cadeia produtiva da carne bovina, objeto deste estudo, ela vem enfrentando constantes dificuldades, decorrentes da falta de 
subsídios para nortear o setor de forma sistêmica. É consenso na literatura que a cadeia da carne bovina, no Brasil, apresenta baixos níveis de coordenação; a comercialização é um sistema defasado e ineficiente, repleto de oportunismo, assimetria de informações e falta de estabilidade de preços. Aliado a isso, problemas de ordem sanitária e a concorrência desleal de frigoríficos que abatem clandestinamente contribuem para a ineficiência desse sistema (Malafaia et al., 2007, 2006, 2005; Euclides Filho, 2004; Zilbersztajn e Machado Filho, 2003; Rocha et al., 2001, entre outros).

No Estado do Rio Grande do Sul, quarto maior produtor de carne bovina do País (Fürstenau, 2004), os reflexos das questões discutidas anteriormente são percebidos, principalmente, nos resultados agroeconômicos, que na maioria das vezes são negativos, bem como na elevada dependência de rendas não-agrícolas (em especial, decorrentes de arrendamentos e aposentadorias). Igualmente, os sistemas produtivos apresentam, na maioria das vezes, valor da terra relativamente baixo, nível de capital imobilizado baixo, baixa utilização de mão-de-obra e indicadores econômicos baixos ou negativos (SEBRAE/FARSUL/ SENAR, 2005).

Percebe-se que o processo de globalização teve grande impacto na pecuária do Rio Grande do Sul, principalmente em face da concorrência com os países do MERCOSUL, onde muitos produtores foram excluídos do processo produtivo e muitas indústrias faliram. Nota-se, também, que o Estado não está conseguindo enfrentar a concorrência de alguns pólos mais recentes na criação de bovinos, como, por exemplo, os Estados da região Centro-Oeste, no que diz respeito à atividade de exportação de carne bovina, que, pelas exigências do mercado externo, requer maior qualificação no processo produtivo do que a produção para o mercado interno.

Segundo Fürstenau (2004), enquanto a participação do Rio Grande do Sul no total de exportações em 1990 era de 22\%, em 2002 reduziu para menos de 6\%. Esse "espaço" perdido pelo Estado foi ocupado por São 
Paulo, Paraná e pelos Estados da região Centro-Oeste. Essa autora afirma que, sendo as exportações brasileiras de carne bovina in natura um reflexo do grau de evolução do setor, o Estado do Rio Grande do Sul seria o menos dinâmico, porque acompanhou os movimentos dos demais Estados, mas sempre com menor amplitude. Mais ainda, essa falta de eficiência na produção de carne, no Estado, reflete-se numa perda de importância das vendas externas gaúchas em relação aos demais Estados, já que outro movimento claramente identificado em estudos é a rapidez com que outros Estados produtores ocuparam os mercados cedidos pelo Rio Grande do Sul. Nesse contexto, identifica-se claramente a falta de competitividade do Rio Grande do Sul em relação aos Estados concorrentes.

No entanto, nota-se a existência de grande potencial competitivo no Estado, fruto de recursos estratégicos disponíveis em seu território, como a alta genética dos rebanhos; animais alimentados em campo nativo; grandes extensões de campo; boas condições de clima e solo; a presença de indústria exportadora; a expressão das Associações de Produtores; a internacionalmente conhecida Exposição Feira de Esteio; o selo de Indicação de Procedência da Carne produzida na Região da Campanha; o suporte científico-tecnológico das EMBRAPAs; a formação do conhecimento através das universidades; a cultura e a tradição do povo gaúcho, entre outros, mas que necessitam ser trabalhadas de forma coordenada, a fim de obter vantagens competitivas sustentáveis (Malafaia et al., 2006).

Os problemas apontados anteriormente com os quais se defronta a cadeia da carne bovina no Rio Grande do Sul, bem como a possibilidade de reverter esse cenário mediante a eficiente exploração dos recursos estratégicos presentes em seu território, tornam-se elementos instigadores de investigação.

Assim, este estudo teve por objetivo discutir a viabilidade de construção de vantagens competitivas para a pecuária de corte gaúcha no ambiente competitivo do agronegócio, utilizando os recursos territoriais presentes 
no Sistema Agroalimentar Local (SIAL). O SIAL é devidamente contextualizado na segunda parte deste estudo, juntamente com a Teoria da Visão Baseada em Recursos (RBV). No terceiro tópico são apresentados os aspectos metodológicos e, no quarto, busca-se caracterizar um SIAL na pecuária de corte gaúcha, bem como identificar as possíveis vantagens competitivas geradas através dos recursos territoriais disponíveis neste SIAL. Por fim, são apresentadas as considerações finais do estudo.

\section{Revisão da literatura}

\subsection{Sistemas agroalimentares locais}

Conforme mencionado anteriormente, determinadas configurações socioprodutivas podem representar melhores possibilidades de enfrentamento de desafios, proporcionando vantagens competitivas para as empresas. Nesse sentido, Schimitz e Nadvi (1999) afirmam que a abordagem de aglomerados geográficos de empresas, vinculados a uma mesma cadeia produtiva, visando uma eficiência coletiva, que seja sustentada por aspectos institucionais, apresentaria condições para isso.

Nesse contexto, ganha importância o conceito de território, em que se encaixam os aspectos econômicos, políticos, históricos, culturais e socioambientais, para o desenvolvimento de vantagens competitivas. No território se busca realçar traços, como o compartilhamento tanto de visões sobre os problemas e oportunidades quanto de hábitos, rotinas e conhecimentos, bem como a inclinação dos atores à ação coletiva (Lyns, 2004). Nessa ótica, para qualquer abordagem sobre processos de transformações produtivas no setor agropecuário, é importante uma aproximação sistêmica desse processo, em que o território assume uma singular relevância como instrumento de análise. O papel da aproximação geográfica, vinculada a uma aproximação social e organizacional, tem sido ressaltado desde o final dos anos setenta por economistas, no intuito 
de compreender as fortes dinâmicas de desenvolvimento econômico (Requier-Desjardins, 2002).

Segundo Boucher et al. (2002), numa perspectiva de desenvolvimento local, o território pode ser abordado sob três dimensões complementares: como espaço físico; como uma instância de articulação de atores; e como uma visão histórica e cultural. Ao considerar o território como uma dimensão física, está-se delimitando espacialmente a região onde serão estabelecidas políticas de desenvolvimento. Ao considerar o território como um cenário onde se articulam diversos atores, dá-se ênfase à dinâmica própria de uma realidade relacional, construída através do tempo, na qual os agentes intervêm, impondo determinadas lógicas de produção. Por último, a construção coletiva do espaço define costumes, práticas, rotinas e experiência acumulada, que tem nos produtos uma forma diferenciada de produzi-los.

Para Schimitz e Nadvi (1999), a concentração geográfica é um facilitador de novas conquistas; entretanto, é necessária uma coordenação para o desenvolvimento de mão-de-obra qualificada, divisão adequada do trabalho, controle da qualidade dos produtos, padronização da produção do arranjo e conquistas de órgãos técnicos de apoio ou formação de órgãos competentes dentro do arranjo. As relações entre fornecedor e produtor podem ser padronizadas, facilitando a ação coletiva no combate a problemas comuns diretamente, através de instituições de auto-ajuda, e indiretamente, por meio dos governos locais, desenvolvendo uma relação de confiança entre os membros do arranjo.

Na visão de Lyns (2004), o conceito de território significa, por extensão, colocar em primeiro plano a territorialidade, percebida como conjugação de ativos específicos, dificilmente encontrados com as mesmas características em outros locais. Entende-se por ativos específicos aqueles recursos essenciais disponíveis no território, para as atividades produtivas. Esses ativos podem ser caracterizados através do conhecimento tácito difundido no arranjo local, da identidade sociocultural e das instituições presentes. 
No caso do setor agroalimentar, o fato de utilizar os recursos naturais para produzir alimentos faz com que esses ativos específicos ganhem maior relevância. Os ativos específicos relacionados à produção alimentar geram uma relação específica de proximidade do consumidor em relação ao produto consumido, tornando-se, assim, mais importantes que em outros setores. Essa proximidade desempenha grande papel na avaliação da qualidade dos produtos pelo consumidor (Malafaia et al., 2006). As capacidades cognitivas dos consumidores permitem-lhes a apreensão das características dos produtos que compram. Dessa forma, as características de origem ligadas ao ambiente e à identidade cultural desempenham papel importante. O conjunto das relações que se estabelecem nas filieres entre produtores, transformadores, distribuidores e consumidores em redor da construção social da qualidade pode ser considerado como um ativo específico territorial, a partir do momento em que as "convenções de qualidade" são ligadas originalmente ao território do produto (Requier-Desjardins, 2002).

Nessa linha de raciocínio, tem sido desenvolvido um conceito que, numa visão sistêmica, vincula as atividades da agricultura a territórios específicos e que trata de integrar elementos relacionados ao ambiente, à organização das sociedades rurais, à qualidade dos alimentos etc. A preocupação de investigar as inter-relações existentes entre o desenvolvimento agroalimentar local e as dinâmicas territoriais deu amplitude ao conceito de Sistemas Agroalimentares Locais (SIAL), que está diretamente relacionado com o sistema de produção alimentar local, onde o território se converte em um ator histórico e social importante (Requier-Desjardins, 2002; Boucher et al., 2000).

Segundo Requier-Desjardins (2002), os SIAL são concentrações locais de pequenas empresas de transformação agroalimentar que apresentam as seguintes características: a) freqüentemente são orientados para a produção de produtos cuja qualidade é ligada originalmente ao território; b) são baseados nos ativos específicos, recursos comuns à disposição dos atores destes sistemas, de diversas ordens; c) realizam freqüentemente uma produção coletiva de bens privados e públicos; e d) 
podem ser identificados, ao mesmo tempo, em diversos países. A imagem do território é o ponto fundamental para a sustentação dos SIAL, sendo, portanto, objeto de interesse generalizado entre os agentes.

Nesse sentido, a cooperação entre empresas de um determinado grupo, localizadas geograficamente próximas, aliada à alta especificidade dos ativos presentes no território, são elementos importantes para criar oportunidades e novos espaços de atuação das organizações perante o ambiente competitivo e globalizado (Requier-Desjardins, 2002). Esse conceito abre espaço para a discussão da Teoria da Visão Baseada em Recursos, que visa à construção de vantagens estratégicas, tendo em vista a heterogeneidade dos recursos disponíveis entre as firmas, a qual será discutida a seguir.

\subsection{A visão da firma baseada em recursos}

As primeiras definições de RBV deram-se nos anos 50, com Edith Penrose. Para a autora, uma empresa é vista como "an unique bundle of productive resources" (Penrose, 1959). Esses conjuntos de recursos podem gerar um diferencial competitivo para as firmas, desde que sejam eficientemente administrados. Segundo Barney (1991), as empresas podem diferenciar-se através dos recursos. Se os recursos disponíveis são específicos (raros, escassos, especializados) e capazes de agregar valor aos produtos finais, eles podem gerar um diferencial competitivo.

Os recursos das firmas incluem todos os ativos, capacidades, processos organizacionais, atributos das firmas, informação, conhecimento etc. controlado pela firma, que a habilita a conceber e implementar as estratégias que aperfeiçoam a eficiência e a efetividade (Barney, 1991). Esses fatores devem permitir às firmas criarem valor.

Os recursos podem ser classificados em três categorias: de capital físico, de capital humano e de capital organizacional. Os físicos incluem planta, equipamentos, posição geográfica e acesso a materiais. Os humanos 
incluem treinamento, experiência, inteligência, arbítrio, percepção individual dos COs. Os recursos de capital organizacional incluem estrutura de informação, planejamento formal ou informal, controle e sistemas de coordenação e as informações relacionadas com o grupo no ambiente.

Nessa ótica, Grant (1991) propõe uma classificação em recursos tangíveis, os quais podem ser observados e avaliados com clareza, como recursos humanos, financeiros e equipamentos, e recursos intangíveis, os quais não podem ser diretamente observados, como o conhecimento, a cultura organizacional, a reputação da empresa, as habilidades tecnológicas ou gerenciais não documentadas e os relacionamentos com fornecedores e clientes, entre outros.

Para uma empresa construir vantagens competitivas é necessário que ela implemente uma estratégia que crie valor, não sendo esta facilmente copiada pelos competidores potenciais. Desse modo, o que determina o período da sustentabilidade da vantagem competitiva é a inabilidade dos competidores em fazer a cópia. As fontes de vantagens competitivas são sustentadas pela imobilidade e heterogeneidade dos recursos, quando estes não são distribuídos entre as firmas (Barney, 1991). Em síntese, para sustentar as vantagens competitivas, os recursos devem ser heterogêneos e imóveis.

O modelo teórico dos recursos das firmas deve ter quatro atributos empíricos (Peteraf, 1993): ser valoráveis, no sentido de explorar as oportunidades e neutralizar as ameaças do ambiente; ser raros entre uma firma corrente e um potencial competidor; ser imperfeitamente inimitáveis; e não podem ser estrategicamente equivalente, substituível por recursos valoráveis, mas não são raros ou inimitáveis.

Os recursos valoráveis são aqueles capazes de sustentar as vantagens competitivas, quando estas são capazes de implementar a eficiência e efetividade. A análise destes recursos pode ser efetivada pela matriz S.W.O.T.: forças, fraquezas, oportunidades e ameaças. Eles devem 
neutralizar as ameaças do ambiente. Os modelos de base de recursos também se somam a essas características para se entender os processos que sustentam as vantagens competitivas

A raridade dos recursos encontra-se relacionada com a capacidade de implementar a estratégia de criação de valor perante as concorrentes. Determinadas estratégias requerem um pacote de recursos, um mix de capital físico, humano e organizacional para implemento, bem como o talento dos administradores. Se várias indústrias podem usufruir desses recursos, estes podem ser valoráveis, mas não são raros.

Quanto à imitabilidade dos recursos, estes são perfeitamente inimitáveis se: a habilidade das firmas para obter um recurso for dependente de condições históricas; a ligação entre os recursos possuídos pela firma e sua sustentabilidade como vantagem competitiva for causa de ambigüidade; ou se a geração das vantagens dos recursos for socialmente complexa. Conforme Peteraf (1993), os principais limites à competição ex-post envolvem a presença de condições denominadas de imperfeita imitabilidade e imperfeita substituição de um recurso. A capacidade de proteção de um recurso contra a imitação ou substituição depende da ambigüidade causal, da não-codificação do conhecimento ou da existência de dependências de caminho, entre outros.

Barney (2001) desenvolveu oframework VRIO (Tabela 1) com o objetivo de identificar os ativos estratégicos utilizados pelos agentes pertencentes a uma cadeia de valor, bem como para avaliar o potencial competitivo desta. Isso permitiu a ampliação do uso da RBV para arranjos produtivos, deixando de ser somente uma teoria aplicada à firma individual. Nesse sentido, para o referido autor, se os ativos estratégicos são... 
Tabela 1 - O framework VRIO

\begin{tabular}{|c|c|c|c|c|}
\hline Valoráveis & raros & Imitáveis & $\begin{array}{c}\text { Explorados pelo } \\
\text { arranjo }\end{array}$ & Implicações competitiv \\
\hline Não & - & - & \multirow{4}{*}{ Não } & Desvantagem Competit \\
\hline Sim & Não & - & & Paridade Competitivé \\
\hline Sim & Sim & Não & & $\begin{array}{c}\text { Vantagem competitivi } \\
\text { temporária } \\
\end{array}$ \\
\hline Sim & Sim & Sim & & $\begin{array}{c}\text { Vantagem competitivi } \\
\text { sustentável }\end{array}$ \\
\hline
\end{tabular}

Fonte: Barney (2001).

Nesse framework, primeiramente mapeia-se a cadeia de valor agroalimentar, descrevendo seus agentes, as atividades primárias e as atividades de suporte (Porter, 1985). As atividades primárias incluem suprimentos, produção, distribuição, comercialização e serviços de vendas. As atividades de suporte incluem infra-estrutura (legal, serviços, informação, finanças etc.), desenvolvimento tecnológico ( $\mathrm{P} \& \mathrm{D}$, design de produtos), desenvolvimento e gestão dos recursos humanos.

\section{Aspectos metodológicos}

A fim de atender aos seus objetivos, a pesquisa teve uma característica exploratória e descritiva, utilizando-se de técnica de pesquisa bibliográfica e documental. As informações obtidas foram trabalhadas visando verificar as possíveis vantagens competitivas geradas pelos recursos territoriais. Isso permitiu olhar para um caso específico: a Identificação de Procedência da Carne do Pampa Gaúcho da Campanha Meridional.

A diferenciação de produtos agroalimentares a partir de características territoriais é bem fundamentada pela idéia de Sistemas Agroalimentares Locais, os quais têm o território e as características socioculturais como base de sua formação. As características identificadas para o SIAL da Carne do Pampa Gaúcho, visando compor a análise, foram: a) configuração geográfica - visando identificar a formação de uma aglomeração local de pequenas empresas agroalimentares; b) identificação de características intrínsecas ao produto - oriundas do 
território e de outros ativos específicos disponíveis na região geográfica; c) existência de produção coletiva de bens privados e públicos; d) existência de interação entre o âmbito local e o global; e) existência de ações coletivas ligadas ao processo produtivo e outras que extrapolem esse âmbito; f) existência de fatores sociais, culturais e históricos que criam uma identidade comum entre os produtores; g) existência de regulação institucional ligada ao setor produtivo; e h) existência de uma interação real entre o território e a cadeia produtiva, visando a diferenciação do produto.

A construção de vantagens competitivas sustentáveis, mediante o uso de recursos estratégicos territoriais, é fundamentada pelo modelo VRIO, vinculado à teoria da Visão Baseada em Recursos. As características identificadas para compor a análise foram: recursos valoráveis; recursos raros; recursos imperfeitamente inimitáveis; e recursos explorados pela organização.

A Figura 1 resume esquematicamente a estrutura teórica criada, bem como a escolha das características apresentadas acerca do objeto de estudo. 


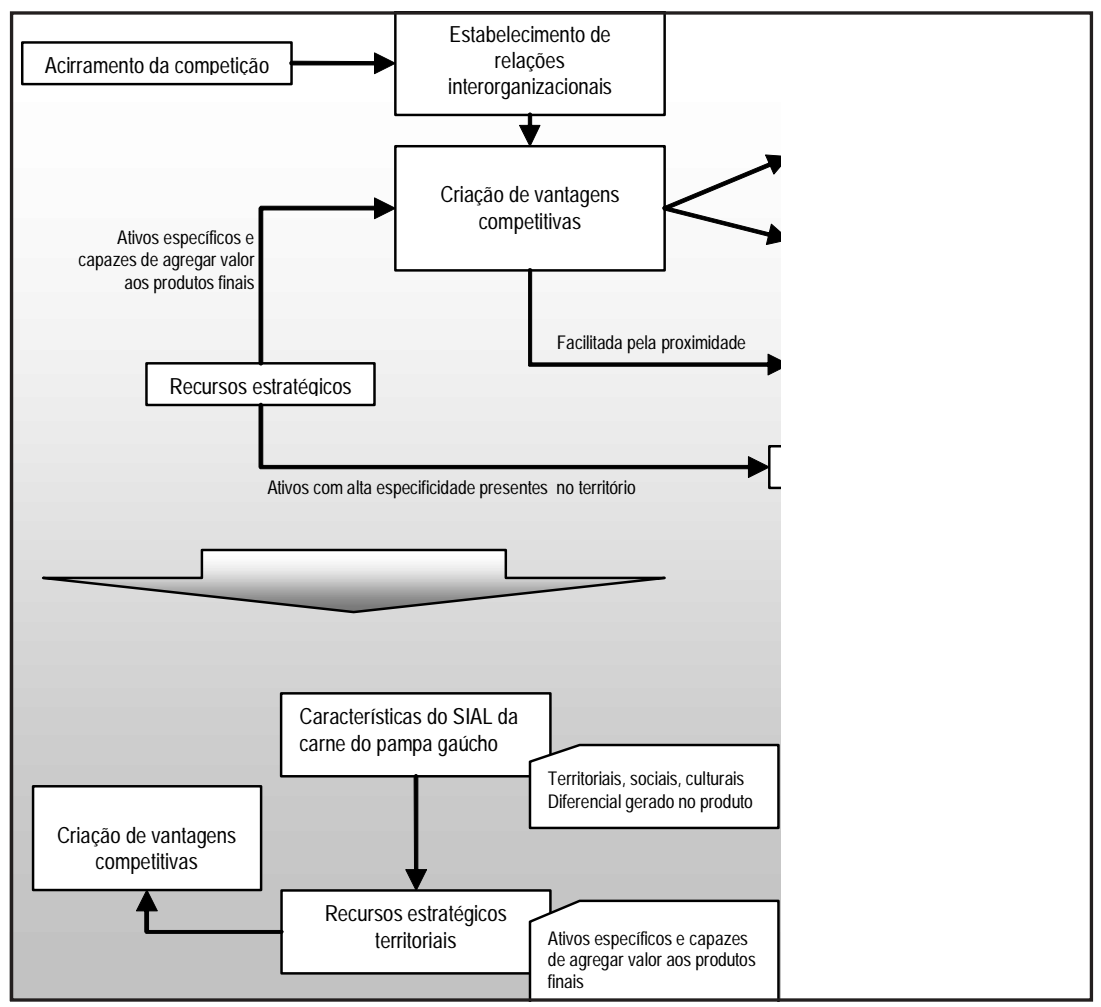

Figura 1 - Esquema analítico utilizado no estudo.

Fonte: Elaborado pelos autores.

\section{Construindo vantagens competitivas para a carne bovina gaúcha}

\subsection{O SIAL da Carne do Pampa Gaúcho da Campanha Meridional}

Na região da Campanha do Estado do Rio Grande do Sul, percebe-se a existência de inúmeros recursos estratégicos disponíveis: sua vocação ganadeira, o privilegiado ecossistema pampa, sua base genética e os 
processos de produção, criação a pasto, abate humanitário, grandes extensões de campo nativo, conhecimento tácito dos produtores, pesquisa agropecuária, cultura e tradição do povo gaúcho, entre outros (Malafaia et al., 2007).

Esses fatores valeram, em dezembro de 2006, o reconhecimento de Indicação de Procedência da "Carne do Pampa Gaúcho da Campanha Meridional", pelo INPI (Instituto Nacional de Propriedade Intelectual). Esses tipos de creditação só foram obtidos no Brasil pelos vinhos produzidos no Vale dos Vinhedos, como indicação de procedência do "Vale dos Vinhedos", e para a região mineira dos cerrados, tradicionalmente produtora de café, como "Café do Serrado". Cabe enfatizar que se entende por Indicação de Procedência um bem originado dentro do território de um país, ou de uma região, onde uma determinada qualidade, reputação ou outra característica do bem é essencialmente atribuível à sua origem geográfica (Barham, 2003).

O projeto da Carne do Pampa Gaúcho começou a ser elaborado em 2004, por meio de uma parceria entre o SEBRAE (Serviço Brasileiro de Aprendizagem Empresarial), SENAR (Serviço Nacional de Aprendizagem Rural), FARSUL (Federação de Agricultura do Rio Grande do Sul), através do programa "Juntos para Competir", UFRGS e EMBRAPA, além de lideranças rurais da região da Campanha Meridional. Na Indicação de Procedência da "Carne do Pampa Gaúcho", foram estabelecidos como área (Figura 2) os municípios de Bagé, Hulha Negra, Dom Pedrito, Lavras do Sul, Candiota, Pedras Altas, Aceguá e Pinheiro Machado (APROPAMPA, 2007). O objetivo do programa de carne certificada é ter um produto diferenciado, por meio da agregação de valor ao rebanho, possibilitando ampliação do mercado consumidor de carne bovina (interno e externo). 


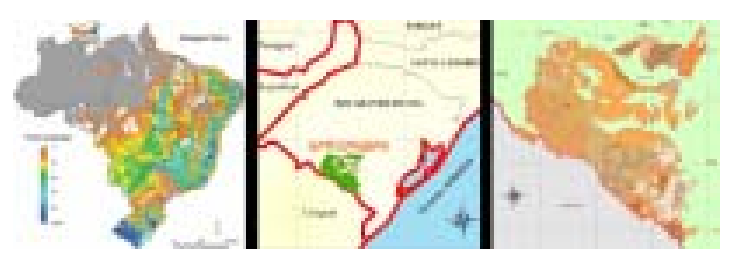

Figura 2 - Mapa da área de produção do "Pampa Gaúcho da Campanha Meridional".

Fonte: APROPAMPA (2007).

Com um produto final de melhor qualidade, acredita-se que o produtor tenha melhor remuneração, podendo assim continuar a investir em programas de qualidade (Malafaia et al., 2007).

Participam atualmente do programa 30 criadores, associados da APROPAMPA - Associação dos Produtores da Carne do Pampa Gaúcho. Essa associação tem a finalidade de acompanhar todo o processo de certificação, funcionando também como um conselho regulador. $\mathrm{O}$ projeto prevê a adesão, até junho de 2007 , de 300 pecuaristas e de um total de mil até junho de 2010. O elo de transformação é composto por uma indústria frigorífica, localizada em Bagé/RS, que projeta realizar 700 abates diários nessa planta. Para dar mais destaque a essa carne, a empresa lançou a marca "Força do Rio Grande", que está integrando a embalagem da carne. A comercialização inicial será por intermédio da rede Wal-Mart, porém será feito um cadastro das empresas interessadas em adquirir o produto, seja para consumo em restaurantes ou venda nas prateleiras. Desde o início dos abates, em dezembro de 2006, o programa Carne do Pampa Gaúcho da Campanha Meridional produziu no período algo em torno de 10 cortes diferentes, totalizando algo ao redor de cinco toneladas. Os cortes mais apreciados foram: picanha, maminha e entrecot (APROPAMPA, 2007). Uma das metas do programa é elevar as exportações de carne in natura para 97 mil toneladas até o final de 2007. 
O selo de Indicação de Procedência da "Carne do Pampa Gaúcho da Campanha Meridional" relata o histórico do animal, sexo, genitores, local, idade, manejo, tipo de alimentação, entre outros. Também atesta o cumprimento de um conjunto de requisitos que garantem a qualidade do produto e que devem ser seguidos em todos os elos da cadeia produtiva (Malafaia et al., 2007).

As características delimitadas na metodologia deste trabalho, quando visualizadas in loco na Região da Campanha do Rio Grande do Sul (Figura 3), permitem afirmar a existência de um SIAL na referida região. Tal afirmação fundamenta-se nos seguintes pressupostos:

a) Configuração geográfica, visando identificar a formação de uma aglomeração local de pequenas empresas agroalimentares Atualmente existem 30 criadores, associados à APROPAMPA. Entretanto, o projeto prevê a adesão de um total de mil até junho de 2010, todos localizados dentro de uma área demarcada e georreferenciada de 1.293.500 hectares, pertencentes a 13 municípios da região da Campanha Meridional.

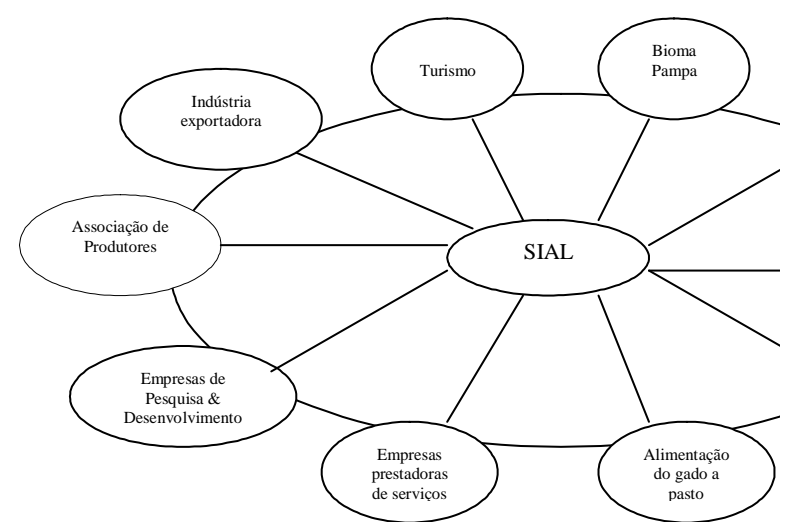

Figura 3 - "Mandala" exemplificativa do SIAL da Carne do Pampa Gaúcho.

Fonte: Dados da pesquisa. 
b) Identificação de características intrínsecas ao produto, oriundas do território e de outros ativos específicos disponíveis na região geográfica - Tradição e cultura, ambiente preservado, produto - rebanho de qualidade reconhecida e desenvolvimento sustentável com pastagens naturais e melhoradas com manejo adequado são os principais ativos específicos encontrados na Campanha Meridional. Isso permite produzir uma carne diferenciada, oriunda de um boi que pasta livre no campo. A característica dessa carne produzida, segundo especialistas, é o sabor específico, diferenciando-a dos outros tipos de carne. Um dos exemplos dessa diferenciação é a não- necessidade do uso de temperos em seu preparo, permitindo assim o consumo de uma carne mais natural.

c) Existência de produção coletiva de bens privados e públicos A carne é produzida sob o selo de Indicação de Procedência "Pampa Gaúcho da Campanha Meridional”' (IP Pampa Gaúcho da Campanha Meridional).

d) Existência de interação entre o âmbito local e o global - Indústria frigorífica com forte imagem e atuação, tanto no mercado interno como no externo. Realização anual da Exposição Feira de Animais, reconhecida internacionalmente pela qualidade dos produtos expostos, e da Festa Internacional do Churrasco.

e) Existência de ações coletivas ligadas ao processo produtivo e outras que extrapolem esse âmbito - A criação da APROPAMPA, uma associação sem fins lucrativos, cultural, social e de pesquisa, formada por produtores rurais, indústria frigorífica, varejo e outros agentes ligados à cadeia da bovinocultura de corte direta ou indiretamente e que tem como o seu principal objetivo a preservação e proteção da indicação geográfica da carne, couro e seus derivados, da região "PAMPA GAÚCHO DA CAMPANHA MERIDIONAL".

f) Existência de fatores sociais, culturais e históricos que criam uma identidade comum entre os produtores - Desde sua ocupação inicial pelas tribos de índios charruas e minuanos, a região da Campanha 
teve na atividade pecuária sua principal fonte de renda. Nos primórdios, as sesmarias deram origem às estâncias destinadas à criação extensiva de gado, onde se produzia couro, charque e lã em grandes extensões de terra. Como resultado desse sistema colonizador, a região caracteriza-se até os dias atuais pela exploração da atividade pecuária, o que permitiu a geração de um conhecimento tácito entre os produtores.

g) Existência de uma regulação institucional ligada ao setor produtivo - Regulamento técnico de qualidade da Indicação de Procedência da Carne do Pampa Gaúcho da Campanha Meridional, conforme artigo $20^{\circ}$ do Estatuto da Associação dos Produtores de Carne do Pampa Gaúcho da Campanha Meridional APROPAMPA.

\subsection{Os Recursos Estratégicos e as Vantagens Competitivas do SIAL da Carne do Pampa Gaúcho da Campanha Meridional}

As características delimitadas na metodologia do presente trabalho, quando visualizadas no SIAL da Carne do Pampa Gaúcho, permitem identificar a existência de recursos estratégicos. Entretanto, é necessário identificar se esses recursos podem ou não gerar um desempenho econômico acima do normal (Quadro 1).

Quadro 1 - Recursos estratégicos identificados

\begin{tabular}{|l|c|c|c|c|c}
\hline \multicolumn{1}{|c|}{ Recursos } & Valoráveis & Raros & Imitáveis & $\begin{array}{r}\text { Explorados } \\
\text { pelo arranjo }\end{array}$ & $\begin{array}{r}\text { Imr } \\
\text { con }\end{array}$ \\
\hline Bioma pampa & $\operatorname{sim}$ & $\operatorname{sim}$ & $\operatorname{sim}$ & $\operatorname{sim}$ & Vantage \\
\hline Genética do rebanho & $\operatorname{sim}$ & não & não & $\operatorname{sim}$ & Paridad \\
\hline Nutrição do rebanho & $\operatorname{sim}$ & $\operatorname{sim}$ & não & sim & Vantag€ \\
\hline Manejo do rebanho & $\operatorname{sim}$ & $\operatorname{sim}$ & $\operatorname{sim}$ & $\operatorname{sim}$ & Vantage \\
\hline Indústria c/ tradição & $\operatorname{sim}$ & não & não & sim & Paridad \\
\hline Tradição e cultura & $\operatorname{sim}$ & $\operatorname{sim}$ & $\operatorname{sim}$ & sim & Vantage \\
\hline Turismo & $\operatorname{sim}$ & $\operatorname{sim}$ & $\operatorname{sim}$ & não & \\
\hline $\begin{array}{l}\text { Empresas Prestadoras } \\
\text { de serviços }\end{array}$ & $\operatorname{sim}$ & não & não & sim & Paridad \\
\hline $\begin{array}{l}\text { Centro de Pesquisa } \\
\text { e Universidades }\end{array}$ & $\operatorname{sim}$ & não & não & sim & Paridad \\
\hline
\end{tabular}

Fonte: Dados da pesquisa. 
Os recursos identificados como proporcionadores de vantagens competitivas sustentáveis referem-se a bioma Pampa, manejo do rebanho, tradição e cultura e à presença de forte associação de produtores. Esses recursos são de ordem sistêmica, ou seja, não pertencem a firmas individuais, sendo compartilhados pelo conjunto de firmas como um todo. Desenvolvem-se através do transbordamento de trajetórias tecnológicas das firmas individuais e são consolidados na forma de conhecimento coletivo. Sua formação se dá por meio de vários processos que podem ocorrer de forma complexa e interligada, marcada geralmente por uma dependência de caminho. Nesse caso, com freqüência está presente uma não-codificação do conhecimento e assimetrias que atuam como barreiras aos potenciais entrantes. Os dois primeiros recursos revelam a importância do papel desempenhado pela produção de carne como precursor de vantagens competitivas, pois nem todos os lugares desfrutam dessas condições territoriais favoráveis, nem do conhecimento tácito presente entre os produtores. Cabe salientar que o turismo ainda é um recurso que não está sendo explorado pelo arranjo produtivo estabelecido para produzir a carne do pampa gaúcho, mas que pode contribuir fortemente para obtenção de vantagens competitivas. Para que os outros recursos estratégicos presentes nesse SIAL se tornem sustentáveis competitivamente, é necessário que haja inovações institucionais, organizacionais e tecnológicas. O resultado seria transparência, valor agregado, menos custos de transação e maior especificidade do ativo.

Um ponto importante a ser destacado refere-se à coordenação desse SIAL, em que a ação coletiva torna-se fundamental para criação de novas oportunidades e novos espaços de atuação para os agentes envolvidos. Para que esse sistema se torne competitivo, é necessário que haja mudança na atitude dos agentes, pois é freqüente o fracasso de experiências que tentam estimular a cooperação entre empresas do mesmo setor numa determinada cidade ou região, dado o problema de comportamento oportunístico. 


\section{Considerações finais}

O presente estudo buscou contribuir para a discussão sobre a inserção da pecuária de corte gaúcha no ambiente competitivo do agronegócio. Ao longo das discussões realizadas, percebe-se uma grande oportunidade para a pecuária de corte através da penetração em nichos de mercados específicos. Nesse sentido, o conceito de SIAL ganha importância, em razão de associar estreitamente produtos típicos e artesanais, técnicas diferenciadas, estilos alimentares, território, recursos naturais, ações coletivas e organização das atividades de produção.

Na região da Campanha Meridional do Rio Grande do Sul, identificou-se a presença de um SIAL, haja vista a referida região dispor de elementos que configuram tal sistema. Percebeu-se que a presença de recursos estratégicos territoriais neste SIAL pode gerar vantagens competitivas para os agentes, dentre as quais podem-se citar: a conquista de nichos especiais de mercado devido à diferenciação da carne produzida; a obtenção de um preço premium pela carne, gerando com isso aumento dos retornos econômicos gerados pela atividade pecuária; e a possibilidade de redução nos custos de transação em face da proximidade dos agentes. Cabe salientar que essas vantagens competitivas são específicas de cada localidade, sendo difíceis de ser copiadas. Os recursos estratégicos presentes no SIAL da Carne do Pampa Gaúcho somente proporcionarão vantagens sustentáveis se forem trabalhados de forma coordenada entre os agentes.

Este trabalho mostrou que é possível enfrentar o ambiente concorrencial da pecuária de corte por meio da abordagem dos aglomerados geográficos. Entretanto, para se vencer nesse ambiente competitivo, todos os segmentos isolados e/ou integrados devem ajustar-se entre si, devendo o conjunto adequar-se às demais variáveis do ambiente geral. Nessa ótica, a construção coletiva de uma coordenação torna-se fundamental para a sustentabilidade desse sistema, pois proporciona conciliação da heterogeneidade dos indivíduos e os seus princípios unificadores, gerando com isso regras e bases de coordenação. 
Como sugestão para estudos futuros, visualiza-se a necessidade de uma discussão sobre como se induzir — ou como se criar — um ambiente de cooperação e confiança entre os agentes. É necessário, também, verificar como se dá a construção social das estruturas de coordenação adequadas para cada arranjo produtivo.

\section{Referências}

APROPAMPA. Regulamento técnico de produção. Disponivel em: www.carnedopampagaucho.com.br/. Consultado em 12/03/2007.

BARHAM, ELIZABETH. Translating terroir: the global challenge of French AOC labeling. Journal of Rural Studies, v. 19, p. 127-138, 2003.

BARNEY, J. Firm resource and sustained competitive advantage. Journal of Management, v.17, n. 1, 1991.

BARNEY, J. B. Resource-based theories of competitive advantage: a ten-year retrospective on the resource-based view. Journal of Management, v. 27, n. 6, p. 643-650, 2001.

BOUCHER, F.; SAUTIER, D.; BRIDIER, B.; MUCHNIK, J.; REQUIER-DESJARDINS, D. Globalización y evolución de la agroindustria rural en América Latina: Sistemas Agroalimentarios Localizados. Serie documentos de trabajo PRODAR No. 10. Lima, Perú: 2000.

COZZARIN, Brian P.; BARRY Peter J. Organizational Structure in Agricultural Production Alliances. In: International Food and Agribusiness Management Review, v.1, n. 2, p. 149-165, 1998.

EUCLIDES FILHO, Kepler. Supply chain approach to sustainable beef production in a Brazilian perspective. Livestock Production Science, v. 90, p. 53-61, 2004. 
FORSMAN, Sari; PAANANEM, Jaana. Local food systems: explorative findings Finland. In: Colloque Syal “ Systèmes Agroalimentaires Localisè" : produts, enterprises et dinamiques locales. 16-18 octobre. Montpellier, France, 2002

FÜRSTENAU, Vivian. Pecuária de corte: baixos índices zootécnicos e eficiência no setor exportador. Indicadores Econômicos FEE / Fundação de Economia e Estatística Siegfried Emanuel Heuser, Porto Alegre. v.32., n.01., 2004.

GRANT, Robert M. “The resource-based theory of competitive advantage: Implications for strategy formulation. California Management Review, Spring, v. 33, p. 114-135, 1991.

LYNS, Hoyedo. Território, Cultura e Inovação. A Ótica dos Sistemas Agroalimentares Localizados. In: IX Encontro Nacional de Economia Política. Uberlândia - MG, 2004.

MALAFAIA, Guilherme Cunha; HANSEN, Peter Bent; BARCELLOS, Julio Otávio Jardim; PINTO, Marcelo Machado B.; TALAMINI, Edson. Analysis of the Inter-Organizational Configurations of Gaucho Beef Cattle Farming. In: International Food and Agribusiness Managemen Association - Proceedings of 16th Annual World Food \& Agribusiness Symposium, Buenos Aires - Argentina, 2006.

MALAFAIA, Guilherme Cunha; BARCELLOS, Julio Otávio Jardim; PEDROZO, Eugenio Ávila; PINTO, Marcelo Machado B. Local AgriFood System as a Mechanism of the Insertion of the Familiar Agriculture in the Competitive Environment. In: International Food and Agribusiness Management Association - Proceedings of 16th Annual World Food \& Agribusiness Symposium, Buenos Aires Argentina, 2006.

MALAFAIA, Guilherme; BARCELLOS, Julio Otávio; AGUIAR, Luis; AZEVEDO, Denise. Building Competitive Advantages for the Livestock farming of Rio Grande do Sul. The Case of the Indication of Origin of 
the "Meat of the Gaucho Pampas". In: International Food and Agribusiness Management Association - 17th Annual World Food \& Agribusiness Symposium, Parma - Italia, 2007.

PENROSE, E. T. The theory of the growth of the firm. New York: Wiley, 1959.

PETERAF, M. A. The cornerstones of competitive advantage: a resource based view. Strategic Management Journal, v. 14, p. 179-191, 1993.

PORTER, M.E. Competitive advantage, New York: The Free Press, 1985.

REQUIER, DESJARDIM, Denis. Multifonctionnalité, territoire et secteur agro alimentaire: une approche par lês "systèmes agroalimentaires localisés". In: CAHIERS DU C3ED. Centre d'Economie et d'Ethique pour l'Environnement et le Développement. Université de Versailles Saint-Quentin-en-Yvelines. Cahier nº2-01. Jun. 2002.

ROCHA, J. C. M. C.; NEVES, M.F. \& LOBO, R. B. (2001). Vertical Alliances: The Case of Beef Chain in Brazil - Proceedings of the Third Internacional Conference On Agri-Food Chain/networks Economics and Management- Faculdade de Economia, Administração e Contabilidade, Campus de Ribeirão Preto - Universidade de São Paulo, 24 a 26 de Outubro. 98 (versão completa disponível no CD Rom do evento e na web).

SCHMITZ, Hubert; NADVI, Khalid. Clustering and industrialization: introduction. In: World Development, vol. 27, n. 9, pp. 1503 - 1514, 1999.

SEBRAE/FARSUL/SENAR (2005). Diagnóstico de sistemas de produção da bovinocultura de corte do Estado do Rio Grande do Sul. Relatório. Porto Alegre. 261 p. 
STERNS, James; PETERSON, Christopher. The Globalization of smaller agri-food firms: a decision - making framework tested through case research. International Food And Agribusiness Management Review, v. 4 , p. 133 - 148, 2001.

ZILBERSZTANJ. D.; MACAHADO FILHO, C. Competitiveness of a meat agri-food chain in Brazil. In: Supply Chain Management, v. 8, n. 2, 155-165, 2003.

\begin{abstract}
This study aims to discuss the feasibility of insertion of the gaúcho livestock farming system in the competitive agribusiness environment, through the Local Agrifood Systems (LAS). In face of the globalization process the transformations incurred by the agribusiness, have hardened the competitiveness of many gaúcho livestock farming enterprises because of their lack of capability in providing new standards as demanded by the market. However, it is perceived a huge opportunity for this activity through the penetration in specific niche markets. The concept of LAS grows in importance, because it is strictly related to strategic resources (craft and typical products; differentiated techniques, styles of feeding, territory; natural resources; collective actions and organization of the productive activities). The results of this study show that a LAs is a viable alternative for the insertion of the gaúcho livestock farming system in a competitive environment. Despite this, problems of coordination of the LAS need to be addressed.
\end{abstract}

Keywords: Local agrifood systems, origin indication, resource-based view, livestock farming. 
REVISTA DE ECONOMIA E AGRONEGÓCIO, VOL.5, No 1 